\title{
Remission of type 2 diabetes: a position statement from the Association of British Clinical Diabetologists (ABCD) and the Primary Care Diabetes Society (PCDS)
}

\author{
DINESH NAGI, ${ }^{1}$ CLARE HAMBLING ${ }^{2}$ ROY TAYLOR ${ }^{3}$
}

\begin{abstract}
This joint Association of British Clinical Diabetologists (ABCD) and the Primary Care Diabetes Society (PCDS) position statement reviews the current evidence related to remission of type 2 diabetes. We believe that there is ample evidence to support the statement that it is possible to achieve remission in type 2 diabetes. In putting this document together, both societies recognise that this is an area of huge clinical significance and has suggested a pragmatic definition of type 2 diabetes and the importance of the proposed definition for clinicians in primary care. This proposal makes firm recommendations about the importance of life style and weight loss in achieving remission of type 2 diabetes and also recognises the different strategies that can be used to achieve remission of type 2 diabetes; however, most of these involve sustained weight loss. This is particularly true in the early stages of type 2 diabetes when irreversible damage to the beta cell has not happened. A further recommendation is that the term 'remission' of type 2 diabetes should be used in preference to other previous terms such as 'diabetes resolved', and should be used for the purpose of clinical coding. It is of key importance that, in those individuals who achieve and sustain remission, robust systems are in place to call and recall these individuals for annual review and that primary care is adequately resourced to facilitate this. Finally, we urge the national and international diabetes societies to work together in further refining the proposed definition as new evidence emerges based on ongoing research.

Br J Diabetes 2019;19:73-76
\end{abstract}

Consultant in Diabetes and Endocrinology and Chair of $A B C D$, Pinderfields Hospital, Mid Yorkshire NHS Trust, Wakefield, West Yorkshire, UK

General Practitioner and Chair of PCDS, Bridge Street Surgery, Downham Market, Norfolk, UK

Professor of Medicine and Metabolism, Newcastle University and Newcastle upon Tyne NHS Trust, Newcastle upon Tyne, UK

Address for correspondence: Dr Dinesh Nagi

Edna Coates Diabetes and Endocrine Unit, Pinderfields Hospital,

Mid Yorkshire NHS Trust, Aberford Road, Wakefield, West Yorkshire,

WF1 4DG, UK

Tel: +44 (0)1294 213594

E-mail: Dinesh.nagi@midyorks.nhs.uk

https://doi.org/10.15277/bjd.2019.221
Key words: remission, type 2 diabetes, weight loss, pathophysiology of type 2 diabetes, beta cell function, weight loss, bariatric surgery

\section{Introduction}

It has been recognised for some time that the processes underlying type 2 diabetes can be reversed and remission of type 2 diabetes can be achieved. The first evidence of this came from studies of bariatric surgery in individuals with type 2 diabetes. ${ }^{1,2}$ Even before then there was evidence that the hyperglycaemia and its associated pathophysiological disturbances can be reversed by adopting a hunter-gatherer lifestyle and this can be achieved within a short period of time. ${ }^{3,4}$ There were sufficient studies showing that, by changing life style dramatically, the control of diabetes can be significantly improved and a significant proportion of patients can either reduce or come off their glucose-lowering therapies..$^{5-7}$

More recent studies have provided further proof of concept that type 2 diabetes can be reversed but, importantly, have demonstrated the underlying mechanism - that is, a reduction in the fat content of liver and pancreas dependent upon beta cell capacity for recovery. ${ }^{8-10}$ Where beta cell failure has already occurred, weight loss is unlikely to be successful in reversing diabetes.

Once achieved, remission appears durable provided weight regain does not occur. This has been formally demonstrated in DiRECT, with clear evidence of gradual continuing improvement in beta cell functional capacity over at least 12 months. ${ }^{10}$ The old idea that beta cell function inevitably declines over time in people who have developed type 2 diabetes has been definitively disproven. Metabolic control has been shown to be maintained over several years if remission is first achieved..$^{11-13}$ The study by Lim et a ${ }^{/ 8}$ was first presented to the 2010 meeting of the Association of British Clinical Diabetologists (ABCD), reporting the index case of dietinduced remission of type 2 diabetes - now known to have remained normoglycaemic 14 years after stopping glucose-lowering therapies. Describing such people as not having diabetes is important not only for insurance purposes but also as a motivating factor to avoid weight regain. The clinical state after weight loss-induced remission of type 2 diabetes is important to differentiate from prediabetes. The term 'remission' retains the implication that there is susceptibility of a return of diabetes if weight regain occurs, whilst indicating that the major cardiovascular risks associated with pre-diabetes are not present - even if plasma glucose might usually 
remain in the range associated with the high-risk state of prediabetes. ${ }^{14}$ This is because the underlying lipid abnormalities driving on the macrovascular risk have been corrected. In UK primary care the Read code CP10 would appropriately be assigned, indicating remission of diabetes but continuing need for annual checks. ${ }^{15}$

However, defining cure or remission of type 2 diabetes has not achieved consensus among international societies. In 2009 the American Diabetes Association (ADA) produced a commentary and statement by an expert group which concluded with a summary of consensus achieved by this group and recommendations to define partial remission and full remission. ${ }^{16}$ Subsequently, Diabetes UK published a brief interim position statement and concluded that it was not possible to achieve consensus and further work was planned.

This position statement by the Association of British Clinical Diabetologists $(A B C D)$ and the Primary Care Diabetes Society (PCDS) was commissioned after discussions with Diabetes UK and agreement with $A B C D$ and PCDS committee members. It is our understanding that further work is planned in the foreseeable future. $A B C D$ and PCDS have therefore taken a pragmatic approach and looked at the available research to date and produced this position statement. The views in this paper are those of the authors and endorsed by members of the ABCD and PCDS committees.

In strict medical terms, cure can be defined as restoration of health and no evidence of the disease process as evidenced by whatever available criteria to diagnose the disease or condition in question. However, medical remission is defined as absence of signs and symptoms of the disease (thyrotoxicosis due to Graves' disease is a good example). Therefore, it is implied that disease can recur at any time in the future. This is particularly true of type 2 diabetes.

Type 2 diabetes has been regarded as a chronic condition and, in this context, remission would appear to be a favourable term while considering the risk of future relapse. The central and important argument is: should the remission of diabetes be defined as return to normal glucose tolerance or at levels of glycaemia which may not be normal, but when the risk of chronic microvascular and macrovascular complications is low or absent?

\section{Why is it important to define remission of type 2 diabetes?}

The prime importance of defining remission is the motivation this provides to individuals in striving for freedom from diabetes. Many people with type 2 diabetes want to be certain of removing the social stigma they feel with the label of 'diabetes', of decreasing the number of tablets to be taken, of removing the threat of complications, decreasing the time spent in doctors' waiting rooms and avoiding the excess costs applied to holiday and life insurance. A further major reason for defining remission is to allow gathering of objective information from medical records for monitoring purposes. There are potentially substantial gains in resources for society and the health economy in general by spending less on medication, monitoring and long-term complications. Any resources thus freed up can be used elsewhere to improve health. Therefore, agreeing a definition of remission may have huge implications.
There are two important considerations underlying a definition of remission:

1. The glycaemic threshold at which remission can be said to have been achieved: should this be at $\mathrm{HbA}_{1 \mathrm{c}}<48 \mathrm{mmol} / \mathrm{mol}$, fasting glucose $<7.0 \mathrm{mmol} / \mathrm{L}$ (the internationally agreed diagnostic threshold for type 2 diabetes) or at $\mathrm{HbA}_{1 \mathrm{c}}<42 \mathrm{mmol} / \mathrm{mol}$, fasting glucose $<6.1 \mathrm{mmol} / \mathrm{L}$, which defines normality according to current diagnostic criteria.

2. The duration over which any given level of glycaemia should be maintained before remission can be diagnosed.

This second point perhaps is more difficult to agree.

ADA has previously proposed the terms: ${ }^{16}$

- Partial remission: return of glycaemia below diagnostic threshold for type 2 diabetes for at least one year.

- Complete remission: where glucose tolerance is normal for at least one year.

In both scenarios these thresholds must be achieved without need for pharmacological treatments. Furthermore, prolonged remission was defined as remission of at least 5 years duration.

$A B C D$ and PCDS are of the view that defining remission in this way has some drawbacks. It is complicated (with two definitions rather than one) and would require a complex coding mechanism, with a need to draw clear distinction between partial and complete remission. This in itself justifies a single definition.

Therefore, we propose a single definition of remission - that is, achievement of glycaemia below the threshold currently used for diagnosis of type 2 diabetes and sustained for a minimum period of 6 months, having discontinued all glucose-lowering therapies. We believe this is a simple and pragmatic definition which will allow a unified application at least in the UK and other health systems.

\section{Recommendation}

Remission of type 2 diabetes can be diagnosed when a person with confirmed type 2 diabetes has achieved all three of the following criteria: (1) weight loss; (2) fasting plasma glucose or $\mathrm{HbA}_{1 \mathrm{c}}$ below the WHO diagnostic threshold $(<7 \mathrm{mmol} / \mathrm{L}$ or $<48$ $\mathrm{mmol} / \mathrm{mol}$, respectively) on two occasions separated by at least 6 months; (3) the attainment of these glycaemic parameters following the complete cessation of all glucose-lowering therapies.

This opinion has been based upon sound information. Development or progression of microvascular complications is unlikely below the threshold for diagnosing diabetes, and indeed this was a major part of the original ADA and WHO reasoning to adopt this diagnostic criterion. ${ }^{17}$ Macrovascular risk is sharply decreased by weight loss, as indicated by 10-year cardiovascular risk (QRISK) decreasing from $23 \%$ to $7 \%$ after 6 months steady weight following diet-induced remission of type 2 diabetes. ${ }^{9,18}$ This remarkable health gain is explained by the improvement in lipid status as well as mean blood pressure and weight. ${ }^{9}$ Both microvascular and macrovascular risks have been shown to decrease sharply after bariatric surgery-induced remission, and microvascular complications regress after pancreas transplantation. 19,20

Does this proposed definition have implications for the healthcare system? Of course, it does. All individuals who achieve remission defined as we propose should and must continue with regular 
surveillance and management of other risk factors as previously agreed for blood pressure and lipid management and also annual screening for complications. However, evidence gathered in the future may help identify individuals who are likely to remain in prolonged remission and those who are likely to relapse. Emerging evidence suggests that the achievement and sustainability of remission is dependent upon the capacity of the beta cell to recover its insulin secretion. ${ }^{10}$

\section{Further care of those who achieve remission}

It is important to recognise that continued support from healthcare professionals is required to maximise the likelihood of long-term avoidance of weight regain ${ }^{21,22}$ and hence the need for regular review once remission is achieved. DiRECT has been followed by a programme of 3-monthly appointments and the success of this will be assessed in due course. Weight regain in the first year was observed to be predominantly early, with only modest regain thereafter. ${ }^{23}$

\section{Evidence-based interventions that are effective in achieving remission}

What are the current evidence-based interventions available to achieve and maintain remission of type 2 diabetes?

1. Bariatric surgery.

2. The introduction of short-term major caloric reduction with total diet replacement and a stepped food re-introduction. It is clear that significant weight loss is a prerequisite to achieving remission of type 2 diabetes, but shorter duration of diabetes is also an important factor associated with successful recovery of residual beta cell function. The DiRECT trial showed that application of dietary modifications aimed at achieving a 12-month remission was a real possibility. ${ }^{23}$

\section{Implications for patients with type 2 diabetes}

Clear-cut criteria to define remission will remove any doubt as to a person's diabetes status for insurance purposes. After undergoing major dietary restriction, it is demotivating to be told that diabetes is still present even though $\mathrm{HbA}_{1 \mathrm{c}}$ is below the diagnostic threshold. Conversely, identification of a threshold focuses the need to avoid weight regain. In addition, we believe that a significant lowering of cardiovascular risk associated with remission must be an additional motivating factor for individuals to sustain remission.

\section{Implications for coding and service provision for those} who achieve remission

Currently, clinical coding for diabetes remission is not widely acknowledged or used. Clear-cut information on the numbers of people who achieve remission of type 2 diabetes and on the subsequent time course will facilitate healthcare planning and resource allocation. Therefore, defining remission is of paramount importance.

\section{Further research}

The ongoing follow-up of DiRECT will provide detailed informa-

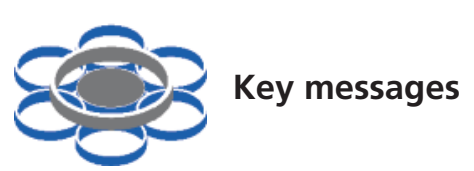

- There is ample evidence to support the statement that it is possible to achieve remission in type 2 diabetes

- Defining remission of type 2 diabetes has not as yet achieved national or international consensus among various organisations and there is no single internationally acceptable definition

- $A B C D$ and PCDS recognise the importance of a consensus definition, which has significant implications for people who achieve remission of type 2 diabetes as well as for health services

- We propose in this position statement a practical definition of remission of type 2 diabetes and call upon other societies to come together to work with us to agree an internationally agreed definition. This will allow an international platform for further research and data collection

- In responsive individuals where type 2 diabetes is associated with weight gain or obesity, remission of type 2 diabetes can be achieved through several means and all require a sustainable weight loss. This is particularly true in the early stages of type 2 diabetes when irreversible damage to the beta cell has not happened

- Once achieved, remission must be sustained to gain the full health benefits

- Of the various strategies shown to be effective, weight loss through bariatric surgery or low calorie diet remain the most successful methods. Both require ongoing sustained modest restriction of energy intake and increase in daily physical activity

- We acknowledge that weight loss achieved by any means, including unintentional weight loss, may contribute to remission of type 2 diabetes

- Implicit in defining remission is that biochemical parameters must have been achieved and maintained following the discontinuation of all glucose-lowering therapies

- We acknowledge that there is considerable debate in the scientific community about the duration over which $\mathrm{HbA}_{1 c}$ or fasting plasma glucose levels must be maintained to define remission. However, we have adopted a pragmatic approach, believing 6 months to be a reasonable duration, aimed at encouraging motivation and sustained weight loss to achieve remission over a longer period.

- Consistent coding for remission of diabetes is required to facilitate safe follow-up and data collection in routine clinical practice.

- $A B C D$ and PCDS strongly recommend that 'diabetes resolved' clinical codes should not be employed in clinical practice but that 'diabetes in remission' codes should preferentially be adopted.

- Finally, it is important that, in those individuals who achieve and sustain remission, robust systems are in place to call and recall these individuals for annual review and that primary care is adequately resourced to facilitate this 
tion about remission of type 2 diabetes up to 5 years. Ongoing collation of clinical data, made possible by the clear definition of remission of type 2 diabetes, will be vital to inform future healthcare and policy decisions.

\section{Conclusions}

Recent evidence has informed our recommendation regarding the definition of remission of type 2 diabetes. Achievement and maintenance of $\mathrm{HbA}_{1 \mathrm{c}}$ of $<48 \mathrm{mmol} / \mathrm{mol}$ (or fasting plasma glucose $<7.0$ $\mathrm{mmol} / \mathrm{L}$ ) after weight loss and the discontinuation of all glucoselowering therapies over 6 months or longer allows a clear evidencebased definition of diabetes remission. The need for ongoing supportive follow-up is implicit in the formal recognition of remission, given the risk of weight regain.

\section{Conflict of interest None. Funding None.}

Acknowledgements The authors are extremely grateful to the following members of the ABCD and PCDS committees who contributed very useful discussion and comments during the generation of this position statement: Peter Winocour, Dev Singh, Vijay Jayagopal, John Lindsay, Dipesh Patel, Andy Macklin and Susannah Rowles on behalf of ABCD; Pam Brown, Nigel Campbell, Kevin Fernando, Martin Hadley-Brown, Lesley Hamilton, Patrick Holmes, Naresh Kanumilli, Stephen Lawrence, David Miller-Jones, Paul Newman, Samuel Seidu, Sanjay Tanna, Jane Diggle, Su Down and Nicola Milne on behalf of PCDS.

\section{References}

1. Pories WJ, Caro JF, Flickinger EG, Meelheim HD, Swanson MS. The control of diabetes mellitus (NIDDM) in the morbidly obese with the Greenville Gastric Bypass. Ann Surg 1987;206:316-23.

2. Sjostrom L, Lindroos $A K$, Peltonen $M$, et al. Lifestyle, diabetes, and cardiovascular risk factors 10 years after bariatric surgery. N Engl J Med 2004; 351:2683-93. https://doi.org/10.1056/NEJMoa035622

3. Bouchardat A. De la Glycosurie ou Diabète Sucré. Paris: Baillière, 1875.

4. Sheth H, Sheth J, Sheth F, Burn J. The poor patient with diabetes 'should live like a saint'. Diabet Med 2016;33:134-5. https://doi.org/ 10.1111/dme.12826

5. Wing RR, Blair E, Marcus M, Epstein LH, Harvey J. Year-long weight loss treatment for obese patients with type II diabetes: does including an intermittent very-low-calorie diet improve outcome? Am J Med 1994;97:35462.

6. Wing RR, Marcus MD, Salata R, Epstein LH, Miaskiewicz S, Blair EH. Effects of a very-low-calorie diet on long-term glycemic control in obese type 2 diabetic subjects. Arch Intern Med 1991;151:1334-40.

7. Henry RR, Schaeffer L, Olefsky JM. Glycaemic effects of intensive caloric restriction and isocaloric refeeding in non-insulin dependent diabetes mellitus. J Clin Endocrinol Metab 1985;61:917-25.
8. Lim EL, Hollingsworth KG, Aribisala BS, Chen MJ, Mathers JC, Taylor R. Reversal of type 2 diabetes: normalisation of beta cell function in association with decreased pancreas and liver triacylglycerol. Diabetologia 2011; 54:2506-14. https://doi.org/10.1007/s00125-011-2204-7

9. Steven $S$, Hollingsworth KG, Small PK, et al. Very low calorie diet and 6 months of weight stability in type 2 diabetes: pathophysiological changes in responders and nonresponders. Diabetes Care 2016;39:158-65. https://doi.org/10.2337/dc15-0750

10. Taylor R, Al-Mrabeh A, Zhyzhneuskaya S, et al. Remission of human type 2 diabetes requires decrease in liver and pancreas fat content but is dependent upon capacity for beta cell recovery. Cell Metab 2018;28:547-56.e3. https://doi.org/10.1016/j.cmet.2018.07.003

11. Taylor R. Calorie restriction and reversal of type 2 diabetes. Expert Rev Endocrinol Metab 2016;11:521-8. https://doi.org/10.1080/17446651. 2016.1239525

12. Paisey RB, Frost J, Harvey P, et al. Five year results of a prospective very low calorie diet or conventional weight loss programme in type 2 diabetes. $J$ Hum Nutr Diet 2002;15:121-7.

13. LookAhead Research Group. Eight-year weight losses with an intensive lifestyle intervention: the look AHEAD study. Obesity 2014;22:5-13. https://doi.org/10.1002/oby.20662

14. Taylor R, Barnes AC. Can type 2 diabetes be reversed and how can this best be achieved? James Lind Alliance research priority number one. Diabet Med 2019;36:308-15. https://doi.org/10.1111/dme.13851

15. McCombie L, Leslie W, Taylor R, Kennon B, Sattar N, Lean MEJ. Beating type 2 diabetes into remission. BMJ 2017;358:j4030. https://doi.org/ 10.1136/bmj.j4030

16. Buse JB, Caprio S, Cefalu WT, et al. How do we define cure of diabetes? Diabetes Care 2009:32:2133-5. https://doi.org/10.2337/dc09-9036

17. The Expert Committee on the Diagnosis and Classification of Diabetes Mellitus. Report of the Expert Committee on the Diagnosis and Classification of Diabetes Mellitus. Diabetes Care 1997;20:1183-97.

18. Taylor R, Barnes A. From new understanding of type 2 diabetes to practical management. Diabetologia 2018;61:273-83. https://doi.org/10.1007/ s00125-017-4504-z

19. Pearce IA, llango $B$, Sells RA, Wong D. Stabilisation of diabetic retinopathy following simultaneous pancreas and kidney transplant. Br J Ophthalmol 2000;84:736-40. https://doi.org/10.1136/bjo.84.7.736

20. Sjostrom L, Peltonen $M$, Jacobson $P$, et al. Association of bariatric surgery with long-term remission of type 2 diabetes and with microvascular and macrovascular complications. JAMA 2014;311:2297-304. https://doi.org/ 10.1001/jama.2014.5988

21. Gregg EW, Chen H, Wagenknecht LE, et al. Association of an intensive lifestyle intervention with remission of type 2 diabetes. JAMA 2012; 308:2489-96. https://doi.org/10.1001/jama.2012.67929

22. Wing RR, Phelan S. Long-term weight loss maintenance. Am J Clin Nutr 2005;82(1 Suppl):222S-5S. https://doi.org/10.1093/ajcn/82.1.222S

23. Lean ME, Leslie WS, Barnes AC, et al. Primary care-led weight management for remission of type 2 diabetes (DiRECT): an open-label, clusterrandomised trial. Lancet 2018;391:541-51. https://doi.org/10.1016/ S0140-6736(17)33102-1 